\title{
EMPIRICAL STUDY OF ERP SYSTEMS IMPLEMENTATION COSTS IN SWISS SMES.
}

\author{
Catherine Equey ${ }^{1}$, Rob J. Kusters ${ }^{2}$, Sacha Varone ${ }^{1}$ and Nicolas Montandon ${ }^{1}$ \\ ${ }^{1}$ Haute Ecole de Gestion, 1227 Carouge, Switzerland; ${ }^{2}$ University of Technology and Open University, The Netherlands \\ catherine.equey@hesge.ch; r.j.kusters@tm.tue.nl; sacha.varone@hesge.ch; nicolas.montandon@hesge.ch
}

\begin{abstract}
Keywords: $\quad$ ERP implementation; cost drivers; Swiss SMEs.
Abstract: $\quad$ Based on the sparse literature investigating the cost of ERP systems implementation, our research uses data from a survey of Swiss SMEs having implemented ERP in order to test cost drivers. The main innovation is the proposition of an additional classification of cost drivers that focuses on the enterprise itself, rather than on ERP. Particular attention is given to consulting fees as a major factor of implementation cost and a new major cost driver has come to light. "Consultant experience", not previously mentioned as such in literature, appears as an important aspect of ERP implementation cost. Particular attention must be paid to this factor by the ERP implementation project manager.
\end{abstract}

\section{INTRODUCTION}

One of the main questions asked by management in charge of an Enterprise Resource Planning (ERP) project is "How much does it cost"? It is very difficult to provide a direct answer to this question and academic literature prefers to investigate cost drivers (Kusters, Heemstra and Jonker, 2007); while remaining otherwise scarce on the matter of the level of cost. The aim of this research is to examine factors of implementation cost and specifically the research question "which factors substantially influence ERP implementation cost?"

The issue of factors that impact ERP implementation cost is discussed explicitly by Stensrud (2001). In his research, he wondered if the existing body of knowledge developed for software cost estimation was applicable to estimation of ERP implementation effort.

Several software cost estimation approaches exist, such as the constructive cost model (COCOMO) developed by Boehm (1983). The approach states that under normal circumstances development costs are a function of project size. Since the circumstances in which a project takes place are rarely 'normal', the estimate must be refined using additional cost drivers. As an example, one of the models proposed by Boehm is as follows:

$$
\begin{gathered}
\text { Development costs }=\left(a * c d[\text { size }]^{b}\right) * \\
c d_{1} * c d_{2} \ldots * c d_{14} \\
\text { (where } c d \text { means cost driver) }
\end{gathered}
$$

The cost driver 'size' (cd[size]) is viewed as the most dominant cost driver, not only in COCOMO but also in many other models (Kusters, Van Genuchten and Heemstra, 1990).

Stensrud (2001) concluded that since most software cost estimation (SCE) approaches are based upon the use of the number of lines of source code (Boehm, 1983) or some synthetic variable such as function points (Albrecht and Gaffney, 1983) to assess the size of the project, these approaches are not immediately applicable. An ERP implementation project may contain some software development, but will also contain substantial modelling, installation and reorganization efforts. It seems unlikely that a one-dimensional measure of software size will capture this complexity. He did however conclude, that a measure of size for an ERP implementation project would likely be multi-dimensional; using a combination of measures such as the number of users, the number of reports that have to be designed, and the number of ERP modules.

Stensrud (2001) further concludes, based on a screening of existing SCE tools, that the concepts provided by parametric models such as COCOMO II (“COCOMO II", 1998) provide a good starting point 
for the development of an estimation model. Crucial elements in these models are the existence of a size metric that can be used to estimate 'normal' costs, as well as cost drivers that can adjust for project specific issues. He also concluded that emergent models for estimation of implementation effort of standard software, in particular the COCOTS model ("COCOTS", 2001), may provide valuable support in this area. Empirical works by Francalanci (2001), Von Arb (2001), and Kusters et al. (2007) support this line of reasoning.

The research by Francalanci (2001) is focused on the identification of a usable measure of size. In agreement with Stensrud (2001), she deduces that such a measure should be multi-dimensional. Based on data from $43 \mathrm{SAP} \mathrm{R} / 3$ implementation projects in a number of European companies, she identifies three constituting elements for such a size metric:

- Size of the organization: The size of an organization reflects its inertia, its ability to resist change. The assumption is that the larger and more cumbersome an organization, and in consequence the more inert it is, the more an implementation effort will cost. As measures of organizational size she tested the number of employees and revenue. Both were found to be useful.

- Size of the configuration: The size of the configuration effort is expressed in the number of modules or sub-modules that are to be implemented. The assumption is that effort will increase with the number of modules to be implemented.

- Size of the implementation: Implementation effort is expressed by the number of users involved, since these indicate training and reorganization effort.

Like Francalanci (2001), Von Arb (1997) focuses solely on size. In his research, a multi-dimensional measure based on number of users and number of (sub-) modules is identified. These results are fairly similar to Francalanci's, but do not look at organizational size.

Kusters et al. (2007) looked at both size and at additional cost drivers in an in depth investigation into two companies. The notion that size is multidimensional was supported in both organisations, but the composing metrics were different. It appeared, as exposed in Table 1, that size was perceived as a combination of:

a) A measure related to the amount of work that is involved in configuring the ERP system. For this measure, items such as the number and complexity of transactions, interfaces, reports and the amount of data and data conversion were mentioned. In practice, people perceive "size" related to the configuration effort at a more detailed level (e.g. number of interfaces) than do both Francalanci and Von Arb, who look at the rather coarse measure number of modules.

b) A measure indicating system implementation and business reorganisation costs. Francalanci (2001) refers to this as implementation size. As this "size" increases, more staff needs to be trained and also more people are involved in organisational change efforts. This measure includes items such as number of users, number of user groups.

c) Francalanci's 'size of the organisation' was also referred to explicitly, but notions of number of user groups' or number of departments could be construed as such.

It is unclear how to consider the cost driver number and complexity of business processes mentioned by Organization II. Complex business processes almost certainly have an impact on the configuration effort. Process modelling is a standard part of ERP implementation preparation and a large number of process model metrics are already available (see for example Netjes, Limam Mansar, Reijers, and Van der Aalst, 2007).

Table 1: Results on size related cost drivers.

\begin{tabular}{|l|ll|}
\hline Francalanci; & \multicolumn{2}{|c|}{ Kusters et al: } \\
Von Arb & Organization I & Organization II \\
\hline - № of (sub) & - № of & - № and complexity \\
modules & transactions, & of transactions \\
- size of & - № of & - № and complexity \\
organization & interfaces, & of interfaces \\
- № of users & - № of reports & - № and complexity \\
& - amount data & of reports \\
& conversion & - size and \\
& - № of user & complexity of data \\
& groups & - № of departments \\
& - № of users & - № of users \\
& & - № and complexity \\
& & of business \\
& & processes \\
\hline
\end{tabular}

There seems to be consensus in available literature on the usefulness of a multi-dimensional size related cost driver. There is also some agreement as to the dimensions involved, but definitely more research is required into the metrics to be used for each dimension.

The 'configuration effort' dimension is mentioned by all three references. Francalanci (2001) and Von Arb (1997) used number of (sub) 
modules as a metric, but Kusters et al (2007) rejected this notion and proposed more detailed metrics.

'Implementation effort' is also an accepted dimension. The metric most mentioned is number of users. However, not just training and motivation effort are important. The degree of reorganisation required can be expected to play a role. This is confirmed by Kusters et al (2007), where cost drivers such as fit between organization and product, process maturity and insight in the processes were mentioned as additional cost drivers. This leads to a test of an additional metric: degree of $B P R$.

Organisational size or 'planning effort' is the third dimension that was previously mentioned.

Apart from the size related factors discussed above, people related factors are most likely to impact ERP implementation costs (see Boehm, 1983, and Kusters et al, 1990, for general arguments to this effect; and Kusters et al, 2007, for ERP specific results).

Given the availability of data from a study of Swiss SMEs in 2006 (Equey, 2006), it is interesting to take a closer look at the dimensions involved. The aim is to substantiate these three efforts on the basis of this specific population. As far as we know, this is the only existing empirical study based on a broad based survey of Swiss SMEs.

This section focuses on existing literature. In Section 2, we present the sampling strategy of our survey of Swiss SMEs. Section 3 presents descriptive statistics of our data followed by a correlation analysis. In conclusion, we point out the main findings, the limitations of this study as well as directions for future research.

\section{METHODOLOGY}

The statistical evidence for this study was collected on the basis of a written survey. The first phase of the research consisted of in-depth interviews of Swiss companies from the French speaking part of the country. This multiple case study (Equey \& Rey, 2004) revealed a number of research questions and associated hypotheses that lead to the design of the questionnaire. The questionnaire was conceived with the participation of senior consultants from the four major vendors of ERP solutions for SMEs on the Swiss market (Abacus, Microsoft, Oracle and SAP). The final version of the survey was broken down as follows: contact details, activities and financial information about the company, specificities of implemented ERP, description of the implementation process, project organization, outcome and benefits derived from the use of the ERP system, difficulties and problems encountered.

The main purpose of the survey was to determine the extent to which Swiss SMEs were aware of or have implemented ERP. The questionnaire covered a wide range of topics including implementation and organisational factors but also issues such as user satisfaction, the tools used and the perceived valueadded. In the present paper we focus only on the data pertaining to costs.

More than 4'000 Swiss SMEs were contacted over a six-month period between November 2005 and April 2006 to take part in the nation-wide survey. The questionnaire was written in French, German, Italian and English and was distributed by post. An electronic version was also made available. The French version is included in (Equey, 2006). Other versions are available from the authors.

Contact details for SMEs were obtained from the Swiss federal office of statistics (OFS) and a sample was constructed according to the following three criteria: the size of the company in terms of the number of employees, the sector of activity (secondary/ tertiary) and the linguistic region.

In order to be demographically representative, $75 \%$ of the sample was chosen from the Germanspeaking region of Switzerland, $20 \%$ from the French-speaking region and the remaining 5\% from the Italian-speaking region. In addition, $84 \%$ of the companies surveyed employed from 1 to 49 persons and the remaining $16 \%$ employed between 50 and 249 persons.

To obtain the relatively high response rate of $17.2 \%$, the mailing was followed up by a telephone interview. A total of 687 Swiss SMEs responded to the questionnaire. Of those, $18.2 \%$ indicated the use of an ERP, whereas $81.5 \%$ or 560 declared not using an ERP. These results show a relatively low level of penetration in Swiss SMEs (less than 20\%).

\section{RESULTS AND DISCUSSION}

\subsection{Descriptive statistics}

This paper uses the data from the survey in Equey (2006) and in particular, the sub set of 125 respondent ERP users who had completed the detailed questionnaire. The inquiry revealed certain trends that are summarized below.

The respondents indicated a project timeframe of less than one year in $80 \%$ of cases and even less than 
six months for $53 \%$. These projects generally involve less than $7 \%$ of the company's internal staff and financially represent no more than $1 \%$ of annual revenue in $35 \%$ of cases (cf. Table 2). A further $38 \%$ fall within $1 \%$ and $3 \%$ of annual revenue. On average, 4 modules are implemented in these projects. Unsurprisingly, the finance module is used in over $80 \%$ of cases and the other most frequently utilized modules: Purchasing, HR, Inventory management and CRM appear in over 50\% of responses. On the other hand, the production module is used by fewer than $40 \%$ of respondents, highlighting the preponderance of tertiary sector enterprises in our sample.

The data reveals in most cases a ratio of one (external) consultant employed to each staff member committed to the project. The cost of consulting was under $20 \%$ of the total project cost in $57 \%$ of cases with a further $20 \%$ falling within $50 \%$ of total cost (cf. Table 4b). Consulting cost is clearly the main individual factor of total cost of implementation in ERP projects.

Software user licenses represent roughly $15 \%$ of total project cost in $54 \%$ of cases (cf. Table $4 \mathrm{c}$ ) and the ongoing commitment to maintenance is on average less than $0.5 \%$ of the company's annual turnover (cf. Table 3). Half of the companies revealed that the number of end users of the system was less than 10 and a further $44 \%$ had between 10 and 100 end users.

The overall costs of the projects covered by this survey (Equey, 2006) are shown in Table 2. The results are somewhat surprising since implementation and maintenance costs were expected to be higher. Table 3 lays out the average ongoing costs of the systems implemented and Tables $4 \mathrm{a}, 4 \mathrm{~b}$ and $4 \mathrm{c}$ show a breakdown of the implementation costs.

Table 2: Total cost of implementation of an ERP.

\begin{tabular}{|cc|}
\hline Total cost in \% of revenue & $\%$ of companies \\
\hline Less than $1 \%$ & $35 \%$ \\
Between 1 and 3\% & $38 \%$ \\
Between 3 and 5\% & $14 \%$ \\
Between 5 and 7\% & $2 \%$ \\
Greater than 7\% & $2 \%$ \\
Did not respond & $9 \%$ \\
\hline
\end{tabular}

Table 3: Ongoing costs of an ERP.

\begin{tabular}{|ccc|}
\hline$\%$ of annual revenue & $\begin{array}{c}\text { Outsourcing } \\
\% \text { in category }\end{array}$ & $\begin{array}{c}\text { Maintenance } \\
\% \text { in category }\end{array}$ \\
\hline Less than $0.5 \%$ & $67 \%$ & $64 \%$ \\
Between 0.5 and $1 \%$ & $7 \%$ & $21 \%$ \\
Greater than $1 \%$ & $5 \%$ & $5 \%$ \\
Did not respond & $21 \%$ & $10 \%$ \\
\hline
\end{tabular}

Table 4a: Investment in IT during ERP implementation.

\begin{tabular}{|cc|}
\hline$\%$ of total cost & $\%$ of respondents \\
\hline Less than $5 \%$ & $28 \%$ \\
Between 6 and $10 \%$ & $20 \%$ \\
Between 10 and $20 \%$ & $26 \%$ \\
Greater than $20 \%$ & $17 \%$ \\
Did not respond & $19 \%$ \\
\hline
\end{tabular}

Table 4b: Consulting costs as a percent of total costs.

\begin{tabular}{|cc|}
\hline$\%$ of total cost & $\%$ in each category \\
\hline Less than $20 \%$ & $57 \%$ \\
Between 20 and $50 \%$ & $20 \%$ \\
Between 50 and $70 \%$ & $8 \%$ \\
Greater than $70 \%$ & $6 \%$ \\
Did not respond & $19 \%$ \\
\hline
\end{tabular}

Table 4c: User licenses as a percent of total cost.

\begin{tabular}{|cc|}
\hline$\%$ of total cost & $\%$ in each category \\
\hline Less than $10 \%$ & $34 \%$ \\
Between 10 and $15 \%$ & $20 \%$ \\
Between 15 and $20 \%$ & $11 \%$ \\
Greater than $20 \%$ & $24 \%$ \\
Did not respond & $11 \%$ \\
\hline
\end{tabular}

These findings are interesting in their own right but give no information about the cost drivers involved.

\subsection{Correlation analysis}

In this research, we mainly look at factors that substantially influence ERP implementation costs. Some of the variables poorly fit existing classifications but are significant in terms of their impact; one example is Consultant's level of experience. We therefore propose an additional classification that seems more appropriate within the context of our variables.

The variables are classified into three groups: enterprise characteristics, people and implementation. This classification focuses on the enterprise, rather than on the ERP itself, as previously proposed by Kusters et al (2007) and Francalanci (2001), to assist in the decision making process of enterprises for its cost calculations. 
To ascertain if a relationship exists between the cost of an ERP project and a variable, we use a measure of correlation $r$, which indicates if a linear relationship exists between variables. We also calculate the probability (the $p$-value) that such relationship exists by chance only. As a standard, relationships having a $p$-value of greater than $5 \%$ are deemed to be present by chance only and are thus rejected.

\section{Enterprise characteristics}

The cost of an ERP project has been found to be dependent upon annual sales revenue $r=-0.167$, $p$ (one-tailed) $=0.044$ as well as the fact that the enterprise is a subsidiary of a foreign holding $r=-0.244, p=0.01$. The negative correlation indicates that the increase/decrease of one variable corresponds to the opposite for the other variable. This is normal since the cost has been coded as a percentage of the annual sales and therefore, once a limit has been reached in the amount of money for an ERP system, the percentage of annual sales for the cost decreases. There is also a strong correlation between annual sales and the fact that the enterprise is a subsidiary of a foreign holding $r=-0.321$, $p=0.01$. Therefore, the cost of ERP is found to be lower for these subsidiaries. Those two variables can be considered as a (single) factor for which a relationship exists with the cost.

No evidence of a relationship has been detected between the cost of an ERP project and the number of ERP users, the number of employees or the sector of activity. Prevailing assumptions about "ERP users" cannot be validated with our data.

\section{People}

The cost of an ERP project has been found to be dependent upon the management's involvement $r=0.182, \mathrm{p}=0.029$; the ERP consultant's level of experience $r=-0.241 p=0.006$; the employee's involvement $r=0.171 p=0.033$; the ratio of external consultant by internal employee $r=0.172$, $p=0.038$. It is interesting to note that even if the cost of an experienced consultant is high; his experience will probably decrease the duration of ERP implementation and subsequently the total cost of the project. The involvement of employees in the ERP project increases the cost, but this involvement may probably be considered as a way to facilitate the adoption of a new system.

No evidence of a relationship has been detected between the cost of an ERP project and the employees' qualifications or field of expertise, nor with the project manager's position.

\section{Implementation}

The cost of an ERP project is found to be dependent upon the number of modules to be implemented $\mathrm{r}=0.186, \quad \mathrm{p}=0.022$; Pearson's correlation coefficient indicates a positive relationship between those variables. This justifies, in support of literature, the a priori intuition that as the number of implemented modules increases, so does the cost of an ERP project. There is a less than 3 percent chance that a correlation coefficient this large would exist by chance only.

The cost of an ERP project is also dependent upon the type of module(s) implemented. Indeed, some of the modules are found to be positively correlated to the cost of an ERP project, since their significance values are no more than 0.05 . There is a medium intensity of the relation between those modules and the cost of an ERP project (cf. Table 5).

Table 5: Correlation to cost of ERP project.

\begin{tabular}{|l|c|c|}
\hline Module & $\mathrm{r}$ & $\mathrm{p}$ \\
\hline Procurement (SCM) & 0.260 & 0.005 \\
\hline Production & 0.220 & 0.017 \\
\hline Sales / CRM & 0.274 & 0.003 \\
\hline Inventory & 0.186 & 0.045 \\
\hline
\end{tabular}

ERP modules are shown to be related with a factor analysis. Two main factors have been detected: a first one includes the procurement (SCM) module, the production module, the sales /CRM module and the inventory module; a second one includes the finance module and the human resource module.

The relationship between modules can be summarized as follows, where only significant correlations are shown.

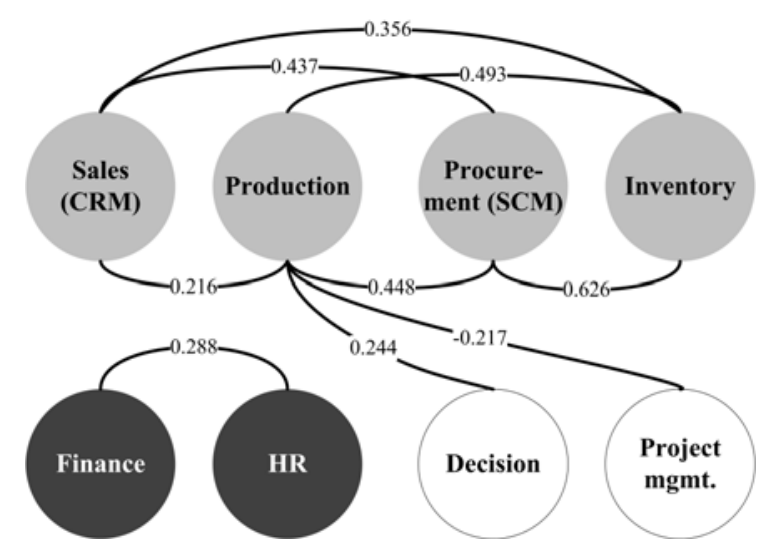

Figure 1: Correlation between modules. 
On the other hand, the results show no strong evidence of a relationship between the cost of an ERP project and the other types of modules individually (i.e. finance, human resources, decision making, project management...). Moreover, no evidence of a relationship has been found with organization tool used or the ERP architecture (web server or client).

\section{CONCLUSION}

This research paper points to some of the factors that may influence the cost of an ERP project. An additional classification of these cost drivers has been introduced that is focused on the enterprise, rather than on ERP.

An important cost driver mentioned in the literature is clearly validated by our analysis: the cost of on ERP project is dependent on the number of modules to be implemented. On the other hand, the interdependence of the number of ERP users and the ERP project cost could not be established with enough reliability through our data. A usual belief is that the cost of the user licenses is a central factor of cost. Nevertheless, our analysis has not revealed evidence of such a relationship. Project managers often, counter productively, "over focus" here to try to generate savings.

The importance of the factor consulting cost clearly stands out in the data and our analysis reveals a new major cost driver, not discussed as such in literature, relating to consultant experience. That people characteristics would impact project costs is not a surprise in itself. However, that this impact is so important, that it ranks with size and can be identified by such a correlation analysis is certainly surprising. Consulting is implicit to other cost drivers such as the number of interfaces or reports and thus deserves investigation. It is interesting to point out the negative correlation found between consultants' experience in ERP and total cost. This result implies managerial and practical consequences concerning the choice of consultants.

As empirical research attempts to measure business perceptions, some limitations or biases are unavoidable. Consequently, as is always the case in empirical research, results should be interpreted with some caution. The extrapolation of these results to large companies is not appropriate, and future research should, therefore, be conducted for them. Further research to construct a multiple regression model will be a next step, in order that managers may evaluate ERP implementation project cost based on enterprise characteristics.

\section{REFERENCES}

Albrecht, A.J., \& Gaffney, J.E. (1983). Software Function, Source Lines of Code, and Development Effort Prediction, IEEE Tr. on Software Engineering, SE9(6).

Arb, R. von (1997). Vorgehensweisen und Erfahrungen bei der Einführung von Enterprise-ManagementSystemen, PhD. Dissertation Universität Bern, Switzerland.

Boehm, B.W. (1983). Software Engineering Economics, Prentice Hall.

COCOMO II, Model Definition Manual (1998). http://sunset.usc.edu/csse/research/COCOMOII/cocom o main.html (Retrieved 20.11.2007)

COCOTS Model Description, (2001). http://sunset.usc.edu/research/COCOTS/index.html (Retrieved 21.11.2007).

Equey, C., \& Rey, A. (2004). La mise en place d'une solution de gestion moderne (ERP/PGI), quels enjeux pour une PME/PMI ? 1ère partie : étude de cas détaillés, Working paper $\mathrm{N}^{\circ} \mathrm{HES}-\mathrm{SO} / \mathrm{HEG}-\mathrm{GE} / \mathrm{C}$-$06 / 1 / 4--\mathrm{CH}$

Equey, C. (2006). Étude du comportement des PME/PMI suisses en matière d'adoption de système de gestion intégré, Working paper $\mathrm{N}^{\circ} \mathrm{HES}-\mathrm{SO} / \mathrm{HEG}-\mathrm{GE} / \mathrm{C}-$ 06/12/1--CH

Francalanci, C. (2001). Predicting the Implementation Effort on ERP projects, Journal of Information Technology, 16(1), 33-48.

Kusters, R.J., HeemstraF.J., \& Jonker, A. (2007). Determining the costs of ERP implementation, Proceedings of the $9^{\text {th }}$ International Conference on Enterprise Information Systems, Vol. Database and Information Systems Integration, 102-110.

Kusters, R.J., Van Genuchten, M., \& Heemstra, F.J. (1990). Are software cost estimation models accurate? Information and Software technology, 32 (3), 187-190.

Netjes, M., Limam Mansar, S., Reijers, H.A., \& Aalst, W.M.P. van der (2007). An evolutionary approach for business process design: towards an intelligent system, Proceedings of the $9^{\text {th }}$ International Conference on Enterprise Information Systems, Vol. Information Systems Analysis and Specification, 47-54.

Stensrud, E. (2001). Alternative Approaches to Effort Prediction of ERP Projects, Information and Software Technology, 43, 413-423. 